\title{
A Representação do Inglês como Língua Franca no Livro Didático do Ensino Médio
}

\author{
The Representation of English as a Lingua Franca in Brazilian \\ High-School Textbooks
}

Jacyara Nô dos Santos*

Instituto Federal de Educação, Ciência e Tecnologia da Babia

Ilhéus, Bahia, Brasil

Maria D'Ajuda Alomba Ribeiro**

Universidade Estadual de Santa Cruz.

Ilhéus, Bahia, Brasil

\begin{abstract}
Resumo: Neste artigo, propomos uma reflexão crítica sobre a perspectiva intercultural apresentada no livro didático de língua inglesa do ensino médio diante da reconhecida percepção deste idioma como uma língua franca global. Para tanto, discutimos algumas implicações pedagógicas que os estudos do inglês como língua franca tem trazido para o processo de ensino-aprendizagem dessa língua de uma maneira geral, buscando nos concentrar num dos principais recursos à disposição de professores e alunos na escola pública: o livro didático. Paralelo à nossa reflexão, apresentamos alguns resultados obtidos a partir da investigação de duas coleções de livros didáticos do ensino médio selecionadas pelo Programa Nacional do Livro Didático de 2015.
\end{abstract}

Palavras-chave: Perspectiva Intercultural. Ensino de Língua Inglesa. Livro Didático.

Abstract: This article aims to reflect on the intercultural perspective in English as a Foreign Language Textbooks used in Brazilian high schools in the view of the acknowledged perception of this idiom as a global lingua franca. For this purpose, we discuss some pedagogical implications that the studies of English as a lingua franca have brought to the teaching-learning process of this language in general, seeking to concentrate on one of the main resources available to teachers and students in the public school: the textbook. Parallel to our reflection, we present some of the results obtained from the investigation of two series of high school textbooks selected by the National Textbook Program of 2015.

Keywords: Intercultural Perspective. Teaching of English. High School Textbook.

\section{INTRODUÇÃO}

O aumento do número de pessoas no mundo com alguma familiaridade com a língua inglesa (doravante LI) como segunda ou terceira língua, como assinala McKay (2003), p. 2), tem permitido que essa língua continue a atuar como uma língua de comunicação para os mais variados propósitos, reafirmando assim seu status como uma língua franca a nível global.

No entanto, apesar da situação da LI há muito comprovar a necessidade de se ter pelo menos algum domínio de expressão nesse idioma, seu ensino na escola pública ainda * Mestre em Letras: Linguagens e Representações pela Universidade Estadual de Santa Cruz (UESC), professora do Instituto Federal de Educação, Ciência e Tecnologia da Bahia - Campus Ilhéus. Email: jacyarano@gmail.com.

** Doutora em Linguística Aplicada pela Universidade de Alcalá, Professor Aposentada da Universidade Estadual de Santa Cruz. 
não é considerado satisfatório e estudantes ainda acreditam, como a maioria da população brasileira, não ser a escola, em particular a pública, o local apropriado para o aprendizado efetivo de línguas estrangeiras (doravante LE). Tal condição sendo reconhecida inclusive pelos documentos norteadores do ensino de LE na educação básica, ao apontarem que

[...] a fala de alunos e dos pesquisadores defendem que o aprendizado de uma língua estrangeira se concretiza em cursos de idiomas, levando-nos a inferir que não há expectativa quanto à escola regular. Ressalvando as possibilidades interpretativas [...], entendemos que os quadros descritos por meio delas [vozes de alunos e pesquisadores] expressam o desejo de que as escolas disponham de condições favoráveis para o ensino de idiomas [...]. (BRASIL, 2006, p. 89).

Neste sentido, entendemos que o reconhecimento do inglês como uma língua franca (doravante ILF) oferece à escola condições favoráveis para um processo de ensinoaprendizado mais efetivo na medida em que desconstrói preceitos do processo de ensinoaprendizagem desse idioma vistos como intocáveis no passado. Dentre esses, destacamos a desconstrução do mito de que todos os aprendizes necessitam ou almejam adquirir competência linguística semelhante à do falante nativo, pois, como já foi salientado por diferentes pesquisadores (GIMENEZ et al, 2015; JENKINS, 2012; SEIDLHOFER, 2005), a LI é utilizada principalmente em situações envolvendo falantes de diferentes línguas maternas e não apenas em interações com falantes de inglês como primeira língua (doravante L1).

A esse respeito, Jenkins (2012, p. 486) ressalta não ser o ILF uma variante da LI no sentido tradicional do termo. Seguindo esta linha, Gimenez et al (2015, p. 594-595), ao discutirem os desenvolvimentos alcançados pelas pesquisas relacionadas ao ILF, salientam que

Embora em uma fase inicial os estudos que tomam como base a expansão mundial da língua inglesa tenham considerado a possibilidade de codificação dessas formas linguísticas como uma variedade, [...], na atualidade esse entendimento parece ser menos defendido.

Dessa forma, esses autores, tomando como base Seidlhofer (2011), assinalam que ILF necessita ser funcionalmente e não formalmente definido, uma vez que não se trata de uma variedade da LI, mas sim uma maneira variável de utilizá-la. Trazendo a discussão para nosso contexto de atuação - o ensino médio - entendemos que estamos preparando nossos estudantes para interagirem em contextos nos quais a LI será utilizada como uma língua franca. Sendo assim, uma abordagem de ensino que busque conscientizar os estudantes acerca da situação desse idioma na atualidade precisa oportunizar a presença da diversidade de contextos culturais no qual esta língua é ensinada e usada.

No que concerne ao ELI, Gimenez, Kalvo e El Kadri (2011) sinalizam que os materiais didáticos ainda se apoiam numa visão da LI como LE, adotando o modelo do falante nativo. Para essas autoras, 
Com o deslocamento do falante nativo e a cultura a ele associada, as propostas pedagógicas para desenvolvimento da interculturalidade poderiam ser melhor detalhadas. [...] os responsáveis pelas políticas educacionais precisam se inteirar do debate que vem ocorrendo especialmente na academia, a fim de reconhecer que mudanças são necessárias, especialmente com relação a questões educacionais. (GIMENEZ et al, 2011, p. 9).

Neste artigo, portanto, reafirmando a necessidade de materiais didáticos que promovam o desenvolvimento da competência intercultural crítica no processo de ELI, propiciando aos estudantes do ensino médio o acesso aos diferentes discursos veiculados por esse idioma, apresentamos alguns resultados obtidos em nossa pesquisa de mestrado (SANTOS, 2016) através da análise de duas obras didáticas aprovadas pelo Programa Nacional do Livro Didático (PNLD) para uso nas escolas públicas de 2015 a 2017.

\section{A PERSPECTIVA INTERCULTURAL NO LD DE LI DO ENSINO MÉDIO}

É notório que o ELI ocorre numa diversidade de contextos. Consequentemente, uma pedagogia adequada para o ELI necessita de uma teoria de ensino e aprendizgem de língua que dê conta de tal diversidade. Para McKay (2003, p. 18-19) a eleição de uma teoria mais abragente para o ensino do ILF necessita levar em conta os seguintes aspectos: (I) a LI é utilizada de diferentes formas por falantes bilíngues para atender a propósitos específicos; (II) muitos falantes de LI não precisam ou não querem adquirir competência semelhante à do falante nativo; (III) a LI não pertence a nenhuma cultura específica.

Trazendo nossa reflexão para o contexto do ELI na educação básica, as Orientações Currículares para o Ensino Médio ${ }^{1}$ (BRASIL, 2006), ao proporem uma retomada da reflexão do ensino de LE, ressaltam que professores e alunos defendem a necessidade da LI no currículo da escola regular em decorrência do mercado de trabalho, das exigências tecnológicas e do fato de ser essa língua o idioma da globalização. O documento concebe, no entanto, ser essa apenas uma visão parcial do que o ensino da LI pode realizar educacionalmente, enfatizando que o aprendizado de uma LE demanda criar meios para que o estudante possa dialogar com outras culturas sem abrir mão de seus valores. Para as OCEM, refletir sobre essas possibilidades

[...] pode nos ensinar sobre os diferentes valores do que é global (universal, exterior, de um grupo de países desenvolvidos, que por sua força político-econômica, se apresentam como modelos sociais) e do que é local (regional, interior, de uma comunidade ou de grupos com características próprias), levando-os a pensar sobre a perspectiva hierárquica entre esses dois modus vivendi e a relativizá-la. (BRASIL, 2006, p. 96).

Observamos assim que os documentos norteadores do ensino de ELI na escola regular se alinham de certa forma com as demandas apresentadas por pesquisas realizadas nessa área. Nesse trecho das OCEM aqui destacado, há a indicação de que o ensino de LE deve orientar-se por uma perspectiva intercultural.

\footnotetext{
${ }^{1}$ Doravante este documento será referido como OCEM.
} 
Uma perspectiva intercultural no ensino de LE, como salienta Mendes (2011, p. 140), requer ver a língua como mais do que um objeto de ensino, pois a perspectiva intercultural demanda ver a língua como "[...] a ponte, a dimensão mediadora entre sujetios / mundos culturais, visto que seu enfoque se dará nas relações de diálogo, no lugar da interação."

Para Mendes (2011), portanto, assim como para outros autores (KRAMSCH, 2012; SOUZA; FLEURI, 2003) que também fundamentam-se em Bhabha (1998), o espaço intervalar da cultura constitui-se como um espaço de intervenção no qual ocorre tensão, negociação e tradução. Dessa forma, para Mendes (2011), o ideal é que conteúdos relativos à cultura sejam abordados não apenas como fatos e informações, mas, principalmente, como redes de significados a serem interpretados. Para tanto, se faz necessário que uma abordagem de ensinar e aprender línguas culturalmente sensível, capaz de transformar professores e estudantes em mediadores culturais e sujeitos de interculturalidade, seja acompanhada de mudança de enfoque com relação aos modos de organização e realização das experiências de ensinar e aprender línguas.

Nesse sentido, o LD, aspecto do ELI no qual nos concentramos neste artigo, utilizado numa perspectiva de ensino intercultural de LE desempenha papel importante na medida em que o plano curricular, em muitos contextos educacionais, como aponta Matsuda (2012b, p. 168), torna-se tangível para professores e estudantes através desse recurso. Trazendo para nossa reflexão a voz de pesquisadores brasileiros, Ramos (2009, p. 173) salienta que como orientador do trabalho desenvolvido na aula de LE, o LD pode moldar ou, em muitos casos, engessar o que acontece na sala de aula. Siqueira (2012, p. 315) por sua vez, nos lembra ser a partir dos materiais didáticos e "[...] com eles que muito do que se faz mundo afora no tocante ao ensino e aprendizagem de línguas se materializa."

Contudo, é necessário não esquecer, segundo Jenkins (2012, p. 487), que apesar do notável aumento no uso do ILF em todas as partes do mundo, a orientação predominante para o ensino e avaliação da LI, assim como para a produção de materiais didáticos permanece incontestavelmente voltada para o inglês dos países do Cículo Interno $^{2}$. Daí a necessidade constante, como aponta Siqueira (2012, p. 316), de nós, profissionais da área de ELI, lançarmos “[...] um olhar crítico sobre todo material instrucional que nos chega às mãos."

Acreditamos que hoje frente ao número de pesquisas e trabalhos que tomam o LD de LE como objeto de estudo, os profissionais da área de ensino estão mais do que cientes de que o LD não só difunde conhecimento, mas também expressa, reforça e constrói uma determinada visão de mundo, desempenhando um papel crucial na construção da percepção e das crenças dos estudantes em relação à língua que está sendo estudada (MATSUDA, 2002, p. 185).

No contexto da escola regular brasileira, a importância atribuída ao LD de LE também tem sido reconhecida pelos editais de convocações para o processo de inscrição

${ }^{2}$ O Círculo Interno, também denominado de Círculo Central, conforme a teoria de expansão da LI no mundo (KACHRU, 1985), corresponde aos países nos quais essa língua é falada como L1. 
e avaliação das obras didáticas do PNLD. Os editais, seguindo a fundamentação teórica dos documentos norteadores do ensino de LE no ensino médio (PCNEM, BRASIL, 2000; OCEM, BRASIL, 2006), explicitam ser o principal objetivo educacional do ensino de LE, nessa etapa de ensino, contribuir para a formação de cidadãos comprometidos com seu entorno e com o de outras realidades sociais.

Dentre os critérios eliminatórios específicos para o componente curricular Língua Estrangeira Moderna (Inglês e Espanhol), os editais de convocações para o PNLD (BRASIL, 2013, 2015) especificam que será observado se a obra "[...] reúne um conjunto de textos representativos das comunidades falantes da língua estrangeira [...]” (BRASIL, 2015, p. 39). Na sequência é ainda estabelecido que a obra didática deve selecionar

[...] textos que favoreçam o acesso à diversidade cultural, social, étnica, etária e de gênero manifestada na língua estrangeira, de modo a garantir a compreensão de que essa diversidade é inerente à constituição de uma língua e das comunidades que nela se expressam [...] (BRASIL, 2015, p. 39).

A presença desses critérios nos permite entender que espera-se que o LD de LE do ensino médio traga para a sala de aula a diversidade de contextos nos quais a LE encontra-se presente. No caso específico do LD de LI, entendemos que espera-se, como aponta Siqueira (2012, p. 316) baseando-se em Matsuda (2005), que as obras didáticas "[...] retirem usos e usuários de inglês das variantes não-nativas e não-hegemônicas da condição periférica, para não dizer quase invisível que ocupam."

Dessa forma, a partir dessas constatações, levando em consideração as implicações que o uso do ILF tem trazido para o ELI, bem como a importância atribuída à cultura no processo de ensino de LE pelos documentos norteadores da educação básica, nosso estudo (SANTOS, 2016) objetivou identificar se os aspectos culturais presentes no LD de LI do ensino médio refletem a condição desse idioma enquanto uma língua franca global, permitindo que nossos estudantes pensem criticamente sobre sua própria cultura e a de outros povos. Dito de outra forma, objetivamos verificar se o tratamento dado à cultura no LD oferece oportunidades para o desenvolvimento da competência intercultural dos estudantes do ensino médio. Para tanto, analisamos duas das quatro obras didáticas aprovadas pelo PNLD 2015.

\section{CONTEXTO DA PESQUISA}

Como assinalamos na seção anterior, a importância conferida ao LD como um recurso à disposição de professores e estudantes para o alcance dos objetivos propostos vem sendo discutida e problematizada em estudos da área da Linguística Aplicada tanto no contexto nacional como internacional. No contexto brasileiro, a coletânea organizada por Dias e Cristovão (2009), intitulada O Livro Didático de Lingua Estrangeira: múltiplas perspectivas, representa uma busca por materiais didáticos de LE de qualidade.

O reconhecimento dessa necessidade indica que, apesar dos diferentes recursos disponibilizados via Internet, o LD 
[...] continua sendo a alternativa mais viável em muitas escolas públicas da educação básica. Para uma grande maioria de alunos e professores, o LD é o material por meio do qual se estabelecem as interlocuções professor/aluno e o conteúdo disciplinar. (DIAS, 2009, p. 199).

A inclusão do LD de LE nas políticas educacionais do Governo, portanto, há muito tempo era esperada por profissionais da área de ensino de línguas no Brasil. Nos últimos anos, tem sido possível observar algumas ações governamentais no intuito de oferecer um ensino médio de qualidade. Dentre essas ações destaca-se a implantação do Programa Nacional do Livro Didático para o Ensino Médio (PNLEM) em 2004. Esse programa foi instituído por meio da Resolução $\mathrm{n}^{\circ} 38$ do Fundo Nacional de Desenvolvimento da Educação (FNDE) e universalizou, de forma progressiva, a distribuição dos livros para os estudantes do ensino médio público de todo país. Os livros de LE, no entanto, tiveram sua entrada no PNLD posteriormente e só passaram a ser distribuídos a partir de 2012.

Para um melhor entendimento da condução de nossa pesquisa, consideramos pertinente lembrar que a seleção das obras didáticas passa por uma avaliação criteriosa por parte de uma equipe composta de professores da educação básica e do ensino superior de diferentes regiões do nosso do país. O Guia de Livros Didáticos PNLD 2015 (BRASIL, 2014, p. 15) para o ensino médio explicita que o conteúdo da ficha de avaliação pedagógica buscou reunir critérios gerais e específicos no intuito de garantir aos avaliadores um instrumento que permitisse o registro de suas observações de forma abrangente sobre cada uma das coleções analisadas.

Com o propósito de atender a todos os critérios comuns e específicos do Edital PNLD 2015 (BRASIL, 2013), a ficha de avaliação foi organizada em duas partes: a primeira, Parte A, refere-se a questões relacionadas aos critérios teórico-metodológicos; a segunda, Parte B, corresponde aos critérios comuns relativos ao respeito à legislação, diretrizes e normas oficiais relativas ao ensino médio e à observância de princípios éticos e democráticos necessários à construção da cidadania e ao convívio social republicano. (BRASIL, 2014, p. 15).

Não iremos aqui explicitar os critérios presentes em cada uma das duas partes dessa ficha, entretanto, consideramos válido informar, para que se tenha uma ideia do esforço empreendido para a avaliação das obras, que a Parte A compunha-se de cinquenta e oito questões e a Parte B de quatro questões relativas aos critérios legais, éticos e democráticos.

Diante de tantos critérios a serem observados, é de se esperar que as coleções selecionadas pelo PNLD apresentem características que as tornem apropriadas para um ensino de LE de qualidade no ensino médio. Menezes (2014, p. 348), autora de um dos livros selecionados pelo PNLD 2015 e, também, pelo PNLD 2018, por exemplo, considera que não há como discordar dos critérios apresentados pelo edital de convocação. Contudo, a autora aponta que alguns desses critérios demandam atenção redobrada por parte dos autores de livros, uma vez que a interpretação dos mesmos pode 
ser bastante subjetiva, tornando ainda mais difícil a tarefa de atender as expectativas dos avaliadores e, posteriormente, as expectativas dos professores.

De igual modo, entendemos que uma avaliação, ou no nosso caso uma análise de um LD, apresenta aspectos subjetivos que podem ser interpretados de diferentes maneiras a depender do posicionamento tomado por quem se propõe a avaliar ou analisar. No entanto, consideramos que apresentar a possibilidade de diferentes leituras não implica que uma dessas leituras possa ser vista como incorreta.

Por outro lado, concebemos que a validade dessas interpretações encontra-se diretamente relacionada com a fundamentação teórica utilizada pelo pesquisador e com os objetivos propostos pela pesquisa. Nesse sentido, considerando ter sido o objetivo principal do nosso estudo, como já explicitado na seção 2 deste artigo, constatar se os aspectos culturais presentes no LD de LI do ensino médio representam a condição desse idioma enquanto uma língua franca global, buscamos aprofundar nosso conhecimento no que diz respeito ao local da cultura no ensino de LE (DOURADO; POSHAR, 2010; KRAMSCH, 2012; MENDES, 2007, 2010, 2015; LIMA; ROEPCKE, 2004; SIQUEIRA, 2011) assim como no que diz respeito às transformações pelas quais o ELI vem passando em decorrência da expansão dessa língua pelo mundo (CLYNE; SHARIFIAN, 2008; JORDÃO, 2011, 2015; KUMARAVADIVELU, 2006; MATSUDA 2012a, 2012b; MCKAY, 2003; RAJAGOPALAN, 2011, 2012; SIQUEIRA, 2011, 2012; TÍLIO, 2014, 2015).

Além disso, realizamos leituras acerca de estudos e pesquisas (MATSUDA, 2009, 2012b; OLIVEIRA, 2012; RAMOS, 2009; REES, 2009; TÍLIO, 2006) voltados para a questão da cultura no LD de LI utilizados em institutos de idiomas e na escola regular. De igual modo, buscamos nos inteirar mais acerca dos documentos oficiais norteadores do ensino de LE nas escolas regulares e dos documentos relacionados ao PNLD no que diz respeito à seleção e avaliação das obras didáticas para o ensino médio.

Antes de passarmos para os procedimentos de análise, entendemos ser importante assinalar que para nossa investigação nos embasamos numa concepção de cultura como algo dinâmico e em constante construção e reconstrução (BRASIL, 2006, p. 97).

\subsection{PROCEDIMENTOS DE ANÁLISE}

Como informado na introdução deste artigo, para condução de nossa pesquisa (SANTOS, 2016), analisamos duas coleções de LD aprovadas pelo PNLD 2015. As duas coleções escohidas foram: High Up (DIAS; JUCÁ; FARIA, 2013) e Take Over (SANTOS, D., 2013).

Para realização da análise dos livros propriamente dita, após a realização da leitura do primeiro volume de cada uma das coleções, decidimos, com base em Tílio (2006), que a identificação e classificação dos tópicos abordados nos livros tornaria possível ter uma percepção do mundo retratado através do LD e, consequentemente, observarmos se, na representação desse mundo, a LI é vista como uma língua de comunicação internacional e, consequentemente, intercultural (SHARIFIAN, 2009, p. 2). 
Para o levantamento dos tópicos, fizemos uma leitura exploratória de todos os volumes correspondentes ao Livro do Aluno das duas coleções e, utilizando contribuições da Análise de Conteúdo (BARDIN, 2011), identificamos e classificamos os tópicos presentes em todas as oito unidades de cada um desses volumes. Embora nossa análise tenha se concentrado no Livro do Aluno, fizemos, também, uma leitura do Manual do Professor de cada um dos exemplares para que tivéssemos condições de entender e interpretar de forma apropriada a proposta de desenvolvimento de cada um dos tópicos apresentados nas unidades dos LD.

Uma vez que nossa investigação se propôs a analisar os livros por completo, não se concentrando apenas em algumas unidades ou determinadas seções, consideramos ser pertinente apresentar de forma condensada os temas abordados em cada um dos volumes. Com esse intuito, resolvemos utilizar dentre as técnicas da Análise de Conteúdo (doravante $\mathrm{AC}$ ), a análise categorial, que consiste no desmembramento do texto em categorias, permitindo a classificação dos elementos de significação constitutivos da mensagem.

Vale reforçar que fizemos uso de contribuições da AC e, portanto, não seguimos rigorosamente os passos da técnica mencionada anteriormente. Entendemos que, ao adotar uma abordagem qualitativa para nossa investigação, foi possível adaptar a metodologia de maneira que pudéssemos atender aos nossos objetivos. Com esse intuito, levando em consideração a necessidade de tornar as mensagens presentes, em nosso corpus, mais acessíveis a fim de podermos manejá-las no decorrer de nossa análise, concebemos que dentre os princípios dessa técnica, nos interessava o fato de possibilitar que os diferentes temas abordados, nos livros, fossem classificados de maneira a tornar possível uma caracterização do mundo aí representado.

Para a categorização dos tópicos, nenhum critério foi estabelecido antes da análise do corpus. A categorização se deu a partir da identificação dos assuntos abordados nos livros e levando em consideração a nossa fundamentação teórica e nossos objetivos.

A análise dos livros das duas coleções possibilitou a identificação e classificação das seguintes categorias de tópicos:

- tópicos includentes, que possibilitam a inserção do aluno no mundo que está sendo criado;

- tópicos tradicionais, que se referem a temas geralmente abordados em materiais de ensino de LE;

- tópicos globalizados, que atravessam fronteiras nacionais e são relevantes para a sociedade global como um todo;

- tópicos etnocentristas, priorizando pessoas (povos), países, culturas e formas de conhecimento particulares;

- tópicos multiculturais, que reconhecem a pluralidade cultural e suas diferenças inerentes;

- tópicos conscientizadores, que se referem a temas indicados pelos documentos norteadores do ensino de LE, na escola regular, e cujo objetivo é contribuir para 
o desenvolvimento da cidadania; dentro dessa categoria, encontram-se também os tópicos que refletem uma postura de ensino crítico da LI, na medida em que buscam mostrar aos estudantes o contexto histórico, cultural e social no qual se insere essa língua;

- tópicos complexos, que estimulam a discussão e o respeito às ideias do outro com relação a assuntos considerados difíceis de trabalhar e debater, em sala de aula, tais como estereótipo, preconceito racial, orientação sexual, desigualdade social etc.

Com exceção da última categorização - tópicos complexos - , todas as demais encontram-se entre as que foram identificadas por Tílio (2006) ao conduzir a análise de seis séries de livros para o ELI. Entendemos que a identificação dos tópicos alocados nesta ultima categorização se explica pelo fato dos documentos oficiais pertinentes ao ensino de LE nas escolas considerarem ser relevante a articulação entre o estudo da LE e o desenvolvimento do comportamento ético, da prática do respeito e do acolhimento ao outro compatíveis com o perfil do estudante do ensino médio (BRASIL, 2015, p. 40).

No que se refere à categoria de tópicos identificada como conscientizadores, em decorrência dos objetivos de nossa investigação, acreditamos ser necessário ampliar seu escopo, incluindo também tópicos que se relacionam com os motivos que culminaram na atual condição da LI. Com relação à categoria identificada como tópicos tradicionais, Tílio (2006) insere nessa modalidade assuntos atemporais enquanto nós incluímos, nesse grupo, os tópicos que costumam aparecer, com frequência, em LD de LI. É importante ressaltar que um mesmo tópico pode reunir características que possibilitem sua inserção em mais de uma das categorias identificadas.

Ainda em consonância com o estudo de Tílio (2006), consideramos que, ao nos referirmos a tópicos, é importante também nos atentarmos para a configuração tópica. Para Brown e Yule (1983, p. 73), da mesma forma que há inúmeras possibilidades de apresentação de um título para um único texto, há também inúmeras formas de se expressar o tópico. Para os referidos autores, cada maneira diferente de se expressar o tópico representa efetivamente um julgamento diferente do que está expresso através de um texto escrito ou falado.

Brown e Yule (1983, p. 74) consideram que a caracterização do tópico possibilita que a forma de expressá-lo possa ser considerada adequada, oportunizando, assim, a incorporação de todas as interpretações razoáveis acerca do que está sendo expresso num determinado discurso. Por essa razão, os autores sugerem que essa caracterização seja desenvolvida em termos de uma configuração tópica, visto que qualquer consideração sobre o tópico envolve questionamentos acerca da razão pela qual algo foi dito em uma situação particular de discurso.

Nos livros analisados, portanto, a categorização foi feita a partir das configurações tópicas identificadas. Consideramos que a representação condensada dos tópicos 
abordados nos LD analisados, como é possível ver no quadro ${ }^{3}$ a seguir, permite que aqueles que ainda não tenham tido contato com esses livros possam ter uma ideia dos temas tratados e a maneira como são desenvolvidos.

\begin{tabular}{|c|l|}
\hline \multicolumn{2}{|c|}{ Take Over 1 } \\
\hline \multirow{2}{*}{ Tópicos } & $\begin{array}{l}\text { - uso de dicionários como ferramenta útil no aprendizado de línguas } \\
\text { - importância do aprendizado de línguas } \\
\text { - língua inglesa como língua de comunicação entre diferentes povos }\end{array}$ \\
\hline Configuração Tópica & $\begin{array}{l}\text { Aprender uma língua estrangeira enriquece nossas visões de mundo. Esse } \\
\text { aprendizado, em particular o da língua inglesa, pode tornar-se mais significativo } \\
\text { através do uso de estratégias úteis e usos adequados da tecnologia. }\end{array}$ \\
\hline \multicolumn{1}{|c|}{ Unidade 2 - Choosing a Career } \\
\hline Tópicos & $\begin{array}{l}\text { - questões que envolvem a escolha de uma carreira profissional } \\
\text { - carreiras com maior demanda nos Estados Unidos }\end{array}$ \\
\hline Configuração Tópica & $\begin{array}{l}\text { Questões a serem consideradas durante a escolha de uma carreira profissional e } \\
\text { os recursos utilizados para se obter informações e apoio durante essa escolha. }\end{array}$ \\
\hline \multicolumn{2}{|c|}{ Quadro 1 - Tópicos e Configurações Tópicas no livro Take Over 1 }
\end{tabular}

Dessa forma, partindo da configuração tópica dos temas abordados nos livros, nossa análise configurou-se como eminentemente interpretativa e orientou-se a partir de dois critérios eliminatórios específicos observados para avaliação das obras inseridas no Guia de Livros Didáticos PNLD 2105 (BRASIL, 2014) no que diz respeito à apresentação dos aspectos culturais no LD de LE. Esses critérios, conforme o edital PNLD 2015 (BRASIL, 2013, p. 47), apontam ser necessário observar se a obra:

- reúne um conjunto de textos representativos das comunidades falantes da LE, com temas apropriados para o ensino médio, que não veicule estereótipos nem preconceitos em relação às culturas estrangeiras envolvidas, nem às nossas próprias em relação a elas;

- seleciona textos que favoreçam o acesso à diversidade cultural, social, étnica, etária e de gênero manifestada na LE, de maneira a assegurar a compreensão de que essa diversidade é inerente à constituição de uma língua e a das comunidades que nela se expressam.

Esses critérios estão diretamente relacionados ao que nos propomos a verificar nas obras analisadas e foram, na verdade, motivadores para o nosso estudo.

\subsection{ANÁLISE DO CORPUS}

3 Todos os quadros apresentados neste artigo foram retirados da nossa dissertação intitulada Competência Interucultural: Interface no Livro Didático de Língua Inglesa do Ensino Médio (SANTOS, 2016) e foram adaptados de Tílio (2006). 
A análise das duas obras didáticas focalizou os seguintes pontos no mundo apresentado ao estudante do ensino médio pelo LD: (I) percepção da situação da LI como língua de comunicação intercultural; (II) o acesso a discursos de diferentes comunidades que se expressam na LI; e (III) a representação da cultura brasileira. Contudo, neste artigo, iremos nos concentrar apenas nos resultados referentes aos dois primeiros pontos.

Ressaltamos não ter sido nosso propósito estabelecer comparações entre as duas coleções, mas sim analisar cada uma delas tendo como foco o tratamento dado aos aspectos culturais e às relações interculturais. O critério de escolha das duas coleções se deu em função de terem sido essas as que tivemos acesso.

\section{RESULTADOS}

A análise das duas obras didáticas permitiu identificar que o mundo representado pelos LD de LI do ensino médio apresentam características semelhantes, sendo abordados tópicos socialmente relevantes para a realidade dos estudantes, nos quais questões individuais e culturais do mundo contemporâneo são enfatizadas.

Essa constatação, no entanto, não se constitui como algo surpreendente se considerarmos que, para serem selecionados, os livros precisam atender aos critérios estabelecidos pelo PNLD. Mesmo assim, concebemos ser importante reconhecer que os documentos norteadores do ensino de LE na escola regular e, mais diretamente, os critérios estabelecidos pelo PNLD têm contribuído para a construção de uma representação de mundo que possibilite o estudante do ensino médio aprender sobre sua própria cultura a partir do acesso à cultura do outro, quer seja esse outro oriundo de seu próprio país ou de uma outra nação.

Vale lembrar que os resultados obtidos por nossa investigação não objetivou indicar haver uma coleção melhor que outra, pois compreendemos que caberá ao professor selecionar dentre as obras indicadas aquela que considerar mais apropriada ao seu contexto de ensino, pois

[...] a escolha do livro didático implica um compromisso didático-pedagógico, a atenção às circunstâncias histórico-sociais de suas turmas e de sua escola e o entendimento de que se trata de uma produção vinculada a valores, posições, visões de língua, de ensino de língua, de aluno, de professor e de papel de línguas estrangeiras na escola. (BRASIL, 2014, p. 8).

Logo, torna-se evidente que a escolha do livro por parte do professor diz muito a respeito do que considera ser o propósito do ensino de LE. Com relação a isso, consideramos válido lembrar ser possível distinguir a persistência de duas vertentes norteando o ensino de inglês em diferentes contextos da escola regular: de um lado aqueles que são favoráveis ao ensino com foco na leitura, fazendo uso de uma abordagem instrumental; de outro, os que apontam ser possível trabalhar as quatro habilidades linguísticas. Logo, esses dois posicionamentos podem ser identificados nos LD de igual forma. 
Independente da vertente na qual se enquadre o professor, no entanto, priorizar o trabalho com a leitura não implica fazer uso de uma abordagem estritamente instrumental, uma vez que as OCEM (BRASIL, 2006, p. 93) indicam que o trabalho com o texto necessita ir além do trabalho com estratégias de leitura, voltando-se "[...] para a habilidade de construção de sentidos, inclusive a partir de informações que não constam no texto." Por conseguinte, independente do professor considerar ser o papel do ELI, no ensino médio, dar ênfase apenas à habilidade de leitura ou não, é necessário não esquecer que, para os documentos oficiais, o ensino da LE também está voltado para o desenvolvimento da cidadania.

Consequentemente, este documento considera ser papel do ensino de LE, nas escolas, motivar reflexões acerca do lugar de onde o estudante/ cidadão fala na sociedade, de como veio a ocupar essa posição e se deseja transformá-la. Esse posicionamento, independente dos conflitos de objetivos para o ensino de LE nas escolas, nos permite inferir que seu ensino não pode prescindir da presença dos aspectos culturais e de uma valorização da dimensão intercultural. Nesse sentido, consideramos que o LD, colaborador desse processo de ensino, desempenha uma função muito importante ao se constituir como um dos principais recursos utilizados na escola regular.

Tendo sido feitas essas considerações, passamos à apresentação dos resultados obtidos por nossa análise.

No que diz respeito à situação da LI no mundo atual, foi possível constatar que as duas coleções preocupam-se em informar os estudantes acerca da importância de se aprender a LI em decorrência da mesma se configurar como uma língua que permite a inserção das pessoas no mundo globalizado.

No entanto, na coleção Take Over (SANTOS, D., 2013), os textos e atividades referentes à situação da LI na atualidade se encontram posicionados no final da unidade, ou no final do livro, dando a impressão de serem atividades acessórias. Esse posicionamento estimula indiretamente o não comprometimento com a realização das mesmas.

Dentre as seções posicionadas na parte final do livro, identificadas como material suplementar no Manual do Professor, encontra-se a seção Culture Matters. Nela, como é possível observar no quadro abaixo, há muitas informações referentes à expansão da LI pelo mundo, bem como informações motivadoras de debate que podem passar despercebidas em decorrência da posição na qual se encontram. Embora, o Manual do Professor indique que essa seção não deve ser vista como um encarte desconectado do restante do material que compõe a obra, o próprio fato de ser identificado como parte do material suplementar faz pensar o contrário.

\begin{tabular}{|c|l|}
\hline \multicolumn{1}{|c|}{ Take Over 1} \\
\hline \multicolumn{3}{|c|}{ People \& Places } \\
\hline Tópicos & $\begin{array}{l}\text { - a língua inglesa no mundo } \\
\text { - populações nativas da América do Norte, Austrália e Nova Zelândia e o risco } \\
\text { de extinção de suas línguas nativas } \\
\text { - personalidades de nacionalidade inglesa }\end{array}$ \\
\hline
\end{tabular}




\begin{tabular}{|c|c|}
\hline Configuração Tópica & $\begin{array}{l}\text { A situação da língua inglesa no mundo e o risco de extinção de algumas línguas } \\
\text { indígenas. } \\
\text { Personalidades inglesas mencionadas em outras seções do livro. }\end{array}$ \\
\hline \multicolumn{2}{|r|}{ Everyday Life } \\
\hline Tópicos & $\begin{array}{l}\text { - sistemas educacionais nos Estados Unidos, Inglaterra e Brasil } \\
\text { - sistemas de governos em países de LI }\end{array}$ \\
\hline Configuração Tópica & $\begin{array}{l}\text { Diferentes grupos sociais seguem diferentes sistemas e cada um deles tem suas } \\
\text { caraterísticas próprias, vantagens e desvantagens. }\end{array}$ \\
\hline \multicolumn{2}{|r|}{ Cultural References } \\
\hline Tópicos & - símbolos nacionais anglófonos \\
\hline Configuração Tópica & Símbolos que remetem a determinados países de língua inglesa. \\
\hline \multicolumn{2}{|r|}{ Arts } \\
\hline Tópicos & - filmes \\
\hline Configuração Tópica & Sinopse de quatro filmes. \\
\hline \multicolumn{2}{|r|}{ Language \& Communication } \\
\hline Tópicos & $\begin{array}{l}\text { - palavras longas na língua inglesa } \\
\text { - palavras frequentemente escritas com erros ortográficos }\end{array}$ \\
\hline Configuração Tópica & Curiosidades sobre a língua inglesa. \\
\hline \multicolumn{2}{|r|}{ A Brief History of English: chapter 1: Old English } \\
\hline Tópicos & $\begin{array}{l}\text { - história da língua inglesa } \\
\text { - influências deixadas na língua inglesa por seus colonizadores } \\
\text { - inglês antigo }\end{array}$ \\
\hline Configuração Tópica & Breve história sobre a língua inglesa, focalizando o inglês antigo. \\
\hline
\end{tabular}

Através da representação condensada da seção Culture Matters no volume 1 da coleção Take Over (SANTOS, D., 2013), é possível constatar a presença de tópicos conscientizadores logo na primeira subseção, People and Places, ao tratar da presença da LI no mundo e abordar a extinção de algumas línguas nativas, por exemplo. No entanto, o posicionamento desta seção ao final do livro ao longo dos três volumes da coleção não dá visibilidade às atividades aí propostas.

Além disso, embora os três volumes da coleção apresentem textos contendo informações que poderiam gerar debates acerca do papel desempenhado pelo inglês no mundo, grande parte das questões apresentadas são de múltipla escolha e visam, nitidamente, verificar os conhecimentos linguísticos dos estudantes e conscientizá-los do uso de estratégias de leitura. Apesar disso, é possível observar que a coleção Take Over busca apresentar para os estudantes do ensino médio a condição diferenciada do inglês em relação às demais línguas estrangeiras.

Com relação à coleção High Up (DIAS; JUCÁ; FARIA, 2013), ainda que apenas o volume 1 faça menção direta à condição da LI no mundo, conforme mostra o quadro a seguir, o tratamento dado ao tema é abrangente e procura instigar os estudantes a refletirem sobre a presença da LI no Brasil e, em particular, na comunidade na qual os estudantes encontram-se inseridos. Igualmente, ao abordar o tema, a coleção preocupase não só em enfatizar a existência de outras variedades da LI, mas ressaltar a importância de se conhecer outras culturas associadas a esse idioma. 


\begin{tabular}{|l|l|}
\hline \multicolumn{1}{|c|}{ Tópicos } & \multicolumn{1}{c|}{ Categorização } \\
\hline A globalização e a língua inglesa & Globalizado/ Conscientizador \\
\hline $\begin{array}{l}\text { A presença da língua inglesa no dia a dia das } \\
\text { pessoas no Brasil }\end{array}$ & Includente/ Conscientizador/ Globalizado \\
\hline Países nos quais a língua inglesa é falada & Globalizado/ Conscientizador \\
\hline $\begin{array}{l}\text { Diferentes variedades da língua inglesa e } \\
\text { predominância da variedade americana }\end{array}$ & Globalizado/ Conscientizador \\
\hline
\end{tabular}

Quadro 3 - Tópicos referentes à situação da língua inglesa no mundo, Unidade 1, High Up 1

Sendo assim, no tocante à condição da LI no mundo, observamos que o LD do ensino médio procura apresentá-la como uma língua franca da atualidade, não estando, portanto, associada apenas aos países nos quais possui status oficial de L1. O que nos leva ao nosso segundo ponto de análise: o acesso ao discurso de diferentes comunidades que se expressam na LI.

A esse respeito, constatamos que as duas coleções buscam mostrar contextos culturais oriundos de comunidades nos quais esse idioma é utilizado como LE ou segunda língua. No entanto, ainda é perceptível a predominância de contextos associados a países do Círculo Interno, em especial os Estados Unidos e a Inglaterra.

Segundo o Guia de Livros Didáticos PNLD 2015 (BRASIL, 2014, p. 7) a avaliação das coleções pautou-se em uma concepção de ensino de LE associada à formação de cidadãos engajados com seu entorno e com o de outras realidades socioculturais no Brasil e em outros países, seguindo, assim, os preceitos dos documentos norteadores do ensino de LE que recomendam ser necessário oportunizar aos estudantes, no processo de ensino e aprendizagem da LI, o diálogo com outras culturas sem que necessitem abrir mão de seus próprios valores.

No entanto, nossa investigação verificou que, no que diz respeito ao diálogo estabelecido entre as culturas brasileiras e as culturas de outros países, esse diálogo se dá, predominantemente, entre a nossa cultura e as culturas norte-americana e a britânica. Não estamos, através dessa constatação, defendendo que os contextos socioculturais dos Estados Unidos e da Inglaterra devam ser abolidos do LD, afinal, o uso do inglês como uma língua franca também inclui seus falantes nativos.

Contudo, a predominância dos discursos dessas comunidades acaba por silenciar até mesmo o discurso de outros países do Círculo Interno. Dessa forma, nas duas coleções, embora haja textos informando aos estudantes sobre a existência de usuários da LI em outros países, esses usuários não são apresentados de forma significativa. Por essa razão, em alguns momentos, a impressão passada é a de aparecerem a título de representarem uma informação acessória, servindo apenas para reforçar a importância do aprendizado dessa língua como meio de acesso a informação em diferentes regiões do mundo, chegando em alguns casos a parecer que a intenção seja apenas apresentar algumas curiosidades sobre a cultura de países que os estudantes não têm muito acesso.

\section{ALGUMAS CONSIDERAÇÕES}


Conforme assinalamos no início deste artigo, acreditamos que mostrar a diversidade de contextos culturais nos quais a LI é utilizada pode contribuir para um processo de ensino-aprendizagem mais efetivo na escola regular, na medida em que possibilita desenvolver a consciência e a sensibilidade em relação às diferenças representadas por essa língua em termos de formas, usos e usuários, desenvolvendo, assim, o respeito, ou pelo menos, a tolerância a essas diferenças (MATSUDA, 2012b, p. 170).

No que se refere aos estudantes do ensino médio, acreditamos que tal perspectiva possibilita também que os mesmos possam se reconhecer como usuários legítimos dessa língua. Em referência a isto, consideramos que o LD, principal recurso utilizado nas escolas, pode contribuir bastante para isso através de uma representação da LI que possibilite trazer para a sala de aula a diversidade de falantes dessa língua.

A esse respeito, através da análise de duas coleções didáticas selecionadas para o PNLD 2105, constatamos ser possível notar que os LD utilizados no ensino médio apresentam evoluções no que diz respeito à representação de aspectos culturais de comunidades que se expressam na LI, embora esta representação ainda não seja a ideal. Esta mudança está intimamente relacionada aos critérios estabelecidos pelo PNLD.

A predominância de contextos culturais hegemônicos, contudo, ainda é fortemente perceptível e, com certeza, encontra-se ligada à tradição da pedagogia de ELI que ainda se espelha no modelo do falante nativo apesar dos inúmeros estudos dando conta das implicações que a condição do ILF trouxe para o processo de ensino dessa língua.

Nosso estudo, como apontamos em outros momentos, não obejtivou mostrar ser uma obra melhor que a outra, pois entendemos que não existe um LD ideal, mas sim aquele que atende melhor às necessidades e propósitos de estudantes e professores. Concebemos, no entanto, que investigações como a nossa nos permite, além de refletir sobre nossos objetivos ao ensinar a LI, observar se os materiais que têm chegado às nossas mãos refletem de alguma forma as mudanças há muito apontadas como necessárias para o ensino dessa língua.

\section{REFERÊNCIAS}

BHABHA, H. O Local da Cultura. Trad. Myrian Ávila, Eliana Lourenço de Lima Reis e Gláucia Gonçalves. Belo Horizonte: UFMG, 1998.

BARDIN, L. Análise de Conteúdo. Tradução de Luís Antero Reto, Augusto Pinheiro. São Paulo: Edições 70, 2011. 
BRASIL. Parâmetros Curriculares Nacionais: Ensino Médio: Linguagens, Códigos e suas Tecnologias. Secretaria de Educação Média e Tecnológica. Brasília: MEC, 2000. Disponível em: < http://portal.mec.gov.br/seb/arquivos/pdf//14_24.

pdf>. Acesso em: 17 fev. 2015.

. Orientações Curriculares para o Ensino Médio. Volume 1: Linguagens, Códigos e suas Tecnologias. Brasília: Ministério da Educação Básica, 2006. Disponível em: <http://portal.mec.gov.br/seb/arquivos/pdf/book_volume_01_ internet. pdf>. Acesso em: 17 fev. 2015.

Edital de convocação01/2013 - CGPLI Edital de convocação para inscrição e avaliação de obras didáticas para o Programa Nacional do Livro Didático PNLD 2015. Brasília: Ministério da Educação, 2013.Disponível em: <http://www.fnde.gov.br/programas/livro-didatico/livro-didatico-editais>. Acesso em: 07 out. 2014.

. Edital de convocação 04/2015 - CGPLI Edital de convocação para inscrição e avaliação de obras didáticas para o Programa Nacional do Livro Didático PNLD 2018. Brasília: Ministério da Educação, 2015. Disponível em: < file://C:/Users/Jacyara/Downloads/Edital_PNLD_2018_ENSINO_MEDIO_conso lidado_3_Alteracao\%20(1).pdf>.Acesso em: 15 ago. 2017.

.Guia de livros didáticos: PNLD 2015: língua estrangeira moderna: ensino médio. Brasília: Ministérios da Educação, Secretaria de Educação Básica, 2014. Disponível em: <www.fnde.gov.br>. Acesso em: 14 out. 2014.

BROWN, G.; YULE, G. Discourse Analysis. Cambridge: Cambridge University Press, 1983. CLYNE, M.; SAHRIFIAN, F. English as an International Language: Challenges and Possibilities. Position Paper. Australian Review of Applied Linguistics. V. 31, n. 31, Monash University EPress, 2008.

DIAS, R. C. G. Critérios para a Avaliação do Livro Didático de Língua Estrangeira no Contexto do Segundo Ciclo do Ensino Fundamental. In: DIAS, R.; CRISTOVÃO, V. L. L. (Orgs.). O livro didático de língua estrangeira: múltiplas perspectivas. Campinas, SP: Mercado de Letras, 2009. p. 199-234.

DOURADO, M. R.; POSHAR, H.A. A Cultura na Educação Linguística no Mundo Globalizado. In: In: SANTOS, P.; ORTÍZ ALVAREZ, M. L. (Orgs.). Lingua e Cultura no Contexto de Português Lingua Estrangeira. Campinas, SP: Pontes Editores, 2010, p. 33-52.

GIMENEZ, T.; CALVO, L. C. S.; EL KADRI, M. S. (Orgs.). Inglês como língua franca: ensino-aprendizagem e formação de professores. Campinas, SP: Pontes Editores, 2011.

GIMENEZ, T; EL KADRI, M. S.; CALVO, L. C. S.; SIQUEIRA, D. S. P.; PORFIRIO, L. Inglês como língua franca: desenvolvimentos recentes. Disponível em: 
<http://www.scielo.br/pdf/rbla/v15n3/1984-6398-rbla-15-03-00593.pdf>. Acesso em: 10 ago. 2017.

JENKINS, J. English as a Lingua Franca from the classroom to the classroom. Disponível em: $<$ http://web.uniroma1.it/seai/sites/default/files/jenkinsEnglish\%20as20a\%20Lingua\%20Franca.pdf>. Acesso em: 20 ago. 2017.

JORDÃO, C. M. A Posição do Inglês como Língua Internacional e suas Implicações para a Sala de Aula. In: GIMENEZ, T.; CALVO, L. C. S.; EL KADRI, M. S. Inglês como língua franca: ensino-aprendizagem e formação de professores. Campinas, SP: Pontes Editores, 2011. p. 221-252.

Abordagem Comunicativa, pedagogia crítica e letramento crítico - farinhas do mesmo saco? In: ROCHA, C.H.; FRANCO MACIEL, R. (Orgs.). Lingua Estrangeira e Formação Cidadã: Por entre Discursos e Práticas. Coleção Novas Perspectivas em Linguística Aplicada, v. 33. Campinas, SP: Pontes Editores, 2a ed., 2015, p.69-90.

KRAMSCH, C. Culture in foreign language teaching. Iranian Journal of Language Teaching Research. n. 1, 2012. p. 57-78. Disponível em: http: <//faculty.weber.edu/ cbergeson/516/kramsch.2012.pdf>. Acesso em: 6 out. 2014.

KUMARAVADIVELU, B. Understanding Language Teaching: from method to postmethod. New Jersey: Lawrence Erlbaum Associates, 2006.

LIMA, Diógenes Cândido de; ROEPCKE, Y.M. Foreign Language Teachers as Culture Brokers. In: LIMA, D. C. de (Ed.). Foreign-language learning and teaching: from theory to practice. Vitória da Conquista: Edições Uesb, 2004, p. 212-222.

MATSUDA, A. Representation of users and uses of English in beginning Japanese EFL textbooks. JALT Journal. 2002, v. 24, n. 2, p. 182-200.

. Globalization and English Language Teaching: Opportunities and challenges in Japan. The English Language Teacher. 2009, v. 33, n. 7, p. 11-14. Disponível em: < http:/ /jaltpublications.org/tlt/issues/2009-07_33.7>. Acesso em: 30 nov. 2014.

Introduction: Teaching English as an International Language. In: MATSUDA, A. (Ed.). Principles and Practices of Teaching English as an International Language. Bristol, UK: Multilingual Matters, 2012a. Disponível em: <http:// samples.Sainsburysebooks.co.uk/9781847697042_sample_99802.pdf>. Acesso em: 19 out. 2014.

Teaching Materials in EIL. In: MATSUDA, A. (Ed.). Principles and Practices of Teaching English as an International Language. Bristol, UK: Multilingual Matters, 2012b. Disponível em: <https://books.google.com.br/books?/id=

PWyrAgAAQBAJ\&pg=PA169\&lpg=PA169\&dq=Teaching + material + in + EIL\&source =bl\&ots=Utgse9Is 7k\&sig=AZ10nef9 zukgMjjkCjs3c7Zo3A\&hl=ptIWTAH\#v=onepag e\&q=Teaching\%20in\%2EIL\&f= false $>$. Acesso em: 14 out. 2015. 
MENDES, E. A Perspectiva Intercultural no Ensino de Línguas: Uma relação "entreculturas”. In: ORTÍZ ALVAREZ, M.L.; SILVA, K. A. (Orgs.) Linguística Aplicada: Múltiplos Olhares. Brasília, DF: UnB - Universidade de Brasília/ Finatec; Campinas, SP: Pontes Editores, 2007, p. 119-139.

. Por Que Ensinar Língua como Cultura? In: SANTOS, P.; ORTÍZ ALVAREZ, M. L. (Orgs.). Lingua e Cultura no Contexto de Português Lingua Estrangeira. Campinas, SP: Pontes Editores, 2010, p. 53-77.

O Português como Língua de Mediação Cultural: Por uma Formação Intercultural de Professores e Alunos de PLE. In: MENDES, E. (Org.). Diálogos Interculturais: ensino e formação em português língua estrangeira. Campinas, SP: Pontes Editores, 2011. p. 139-158.

A Ideia de Cultura e Sua Atualidade para o Ensino de LE/L2. EntreLinguas. Araraquara, v. 1, n. 2, 2015, p. 203-221. Disponível em: <file://C:/Users/Windows\%207/Downloads/8060-21184-2-PB\%20(1).pdf>. Acesso em: 20 out. 2015.

MCKAY, S. L. Toward an Appropriate EIL Pedagogy: Re-examining Common ELT Assumptions. International Journal of Applied Linguistics. V. 13, n. 1, 2003. Disponível em: $<$ http://www.ugr.es/ isanz/archivos_m3 thodology/articulo

ELIPEDAGOGY.pdf>. Acesso em: 20 nov. 2105.

OLIVEIRA, A.P. Tips for Teaching Culture in a Globalized World. In: LIMA, D. C. de. (Org.). Language and its Cultural Substrate: Perspective for a Globalized World. Coleção: Novas Perspectivas em Linguística Aplicada, vol. 21. Campinas, SP: Pontes Edtiora, 2012, p. 83-107.

RAJAGOPALAN, K. O “World English” - Um Fenômeno Muito Mal Compreendido. In: GIMENEZ, T.; CALVO, L. C. S.; EL KADRI, M. S. Inglês como língua franca: ensinoaprendizagem e formação de professores. Campinas, SP: Pontes Editores, 2011, p. 45-57.

. For the Umpteenth Time, The "Native Speaker": Or, Why the Term Signifies Less and Less in the Case of English as It Spreads More and More Throughout the World. In: : LIMA, D. C. de. (Org.). Language and its Cultural Substrate: Perspective for a Globalized World. Coleção: Novas Perspectivas em Linguística Aplicada, vol. 21. Campinas, SP: Pontes Edtiora, 2012, p. 37-58.

RAMOS, R. C. G. O Livro Didático de Língua Inglesa para o Ensino Fundamental e Médio: Papéis, Avaliação e Potencialidades. In: DIAS, R.; CRISTOVÃO, V. L. L. (Orgs.). O livro didático de língua estrangeira: múltiplas perspectivas. Campinas, SP: Mercado de Letras, 2009. p. 173-198.

REES, D. K.The Adventures of Rovbinson Crusoe e um Livro Didático: A Hermenêutica do Discurso do Colonialismo. In: DIAS, R.; CRISTOVÃO, V. L. L. (Orgs.). O livro didático de 
língua estrangeira: múltiplas perspectivas. Campinas, SP: Mercado de Letras, 2009. p. 149172.

SANTOS, J. N. Competência Intercultural: interface no livro didático de língua inglesa do ensino médio. 2016. 183f. Dissertação (Mestrado em Letras: Linguagens e Representações). Universidade Estadual de Santa Cruz, Ilhéus, Bahia, 2016.

SEIDLHOFER, B.Key concepts in ELT: English as a lingua franca. ELT Journal, 2005, v. 59, n.4, p. 339-341. Disponível em: <http:/ / eltj.oxfordjournals.org//content/59/4/339.full.pdf>. Acesso em: 29 set. 2014. . Understanding English as a Lingua Franca. Oxford: Oxford University Press, 2011.

SHARIFIAN, F. (Ed.). English as an international language: perspectives and pedagogical issues. Bristol, UK: Multilingual Matters, 2009.

SIQUEIRA, D. S. P. Se o inglês está no mundo, onde está o mundo nos materiais didáticos de inglês como língua estrangeira. In: SCHYERL, D.; SIQUEIRA, D. S. P. (Orgs.). Materiais didáticos para o ensino de linguas na contemporaneidade: contestações e proposições. Salvador, EDUFBA, 2012, p. 313-353.

. Inglês como língua franca: o desafio de ensinar um idioma desterritorializado. In: GIMENEZ, T.; CALVO, L. C. S.; EL KADRI, M. S. Inglês como língua franca: ensinoaprendizagem e formação de professores. Campinas, SP: Pontes Editores, 2011, p. $87-$ 115.

SOUZA, M. I. P. de; FLEURI, R. M. Entre limites e limiares de culturas: educação na perspectiva intercultural. In: FLEURI, R. M. (Org.). Educação Intercultural: mediações necessárias. Rio de Janeiro: DP \& A, 2003, p. 53-84.

TÍLIO, R. C. O livro didático de inglês em uma abordagem sócio-discursiva: culturas, identidades e pós-modernidade. 2006. 258f. Tese (Doutorado em Letras) - Pontifícia Universidade Católica do Rio de Janeiro, 2006. Disponível em:http: <//www.maxwell.lambda.ele.pucrio.br/cgibin/db2www//PRG_0490.D2W//INPUT? CdLinPrg=pt>. Acesso em: 14 out. 2014.

\section{LIVROS ANALISADOS}

DIAS, R.; JUCÁ, L.; FARIA, R. High Up: ensino médio. Volume 1. Cotia, SP: Macmillan, 2013.

DIAS, R.; JUCÁ, L.; FARIA, R. High Up: ensino médio. Volume 2. Cotia, SP: Macmillan, 2013.

DIAS, R.; JUCÁ, L.; FARIA, R. High Up: ensino médio. Volume 3. Cotia, SP: Macmillan, 2013. 
SANTOS, D. Take Over 1. 2. ed. São Paulo: Escala Educacional, 2013.

SANTOS, D. Take Over 2. 2. ed. São Paulo: Escala Educacional, 2013.

SANTOS, D. Take Over 3. 2. ed. São Paulo: Escala Educacional, 2013.

Recebido em: 20/08/2017

Aprovado em: 16/11/2017

Publicado em: 30/12/2017 